MATHEMATICAL ASSOCIATION

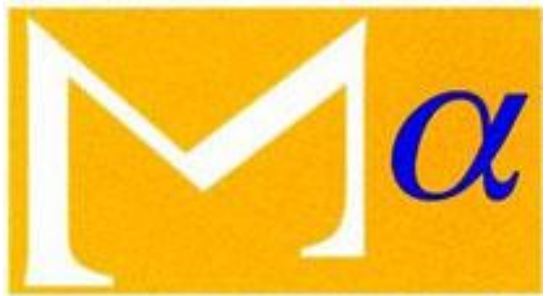

supporting mathematics in education

\title{
127. Elementary Treatment for Gamma Functions
}

Author(s): G. Osborn

Source: The Mathematical Gazette, Vol. 2, No. 40 (Jul., 1903), pp. 311-312

Published by: Mathematical Association

Stable URL: http://www.jstor.org/stable/3605129

Accessed: 12-01-2016 11:48 UTC

Your use of the JSTOR archive indicates your acceptance of the Terms \& Conditions of Use, available at http://www.jstor.org/page/ info/about/policies/terms.jsp

JSTOR is a not-for-profit service that helps scholars, researchers, and students discover, use, and build upon a wide range of content in a trusted digital archive. We use information technology and tools to increase productivity and facilitate new forms of scholarship. For more information about JSTOR, please contact support@jstor.org. 
The formula is in this case :

$3.15 .63 .255 .1023 \cdot \frac{\pi}{2}$

$$
\begin{gathered}
=2^{36} \sin \frac{\pi}{2^{7}}-341.2^{25} \sin \frac{\pi}{2^{6}}+5797.2^{16} \sin \frac{\pi}{2^{5}}-5797.2^{9} \sin \frac{\pi}{2^{4}} \\
+341.2^{4} \sin \frac{\pi}{2^{3}}-2 \sin \frac{\pi}{2^{2^{*}}}
\end{gathered}
$$

The first four terms in the right-hand member of this equation were evaluated from Vlack's ten-figure table of logarithms, the values for the six terms being

$$
\begin{aligned}
& 1,686,460,375 \cdot 5-561,435,335 \cdot 5 \\
& 37,237,906 \cdot 7-\quad 579,040 \cdot 5 \\
& 2,087 \cdot 9-\quad 1 \cdot 4 \\
& =1,723,700,370 \cdot 1-562,014,377 \cdot 4 \text {. }
\end{aligned}
$$

The value of $\pi$ may then be immediately expressed as

$$
\begin{aligned}
& =2 \times \frac{1,161,685,992 \cdot 7}{3 \times 15 \times 63 \times 255 \times 1023} \\
& =\frac{1,161,685,992 \cdot 7}{369,776,637 \cdot 5}
\end{aligned}
$$

or

$$
\pi=3 \cdot 141,592,646 \text {, }
$$

a result which differs in defect of the true value $3 \cdot 1415926535$ by about 1 in $400,000,000$.

R. M. Milne.

\section{MATHEMATICAL NOTE.}

127. [E. 1. a.] Elementary Treatment for Gamma Functions. *

Let

$$
G(n, 1+x) \equiv n^{x} /\left\{\prod_{1}^{n}(1+x / n)\right\}
$$

and

$$
\Gamma(1+x)=G(\infty, 1+x) ;
$$

changing $1+x$ into $x, G(n, x)=n^{x-1} /\left\{\prod_{1}^{n}(1+\overline{x-1} / n)\right\}$.

Thus

$$
G(n, 1+x): x G(n, x)=n: n+x,
$$

and making $n=\infty$,

$$
\Gamma(1+x)=x \Gamma(x) \text {. }
$$

If $x$ is a positive integer, $\quad \Gamma(1+x)=\mid x$.

By definition, putting $x=1$,

$$
G(n, 2)=n /\left\{\prod_{1}^{n}(n+1) / n\right\}=n /(n+1) ;
$$

so when $n=\infty$,

$$
\Gamma(2)=1 \text {. }
$$

Also by (i),

$$
\mathbf{F}(1)=1, \Gamma(0)=\infty \text {. }
$$

Again,

$$
G(n, 1+x) . G(n, 1-x)=\prod_{1}^{n}\left(1-\frac{x^{2}}{n^{2}}\right)^{-1} ;
$$

therefore when $x=\infty, \Gamma(1+x) . \Gamma(1-x)=x \pi / \sin x \pi$.

$$
\text { For } \begin{array}{r}
x=\frac{1}{2}, \Gamma\left(\frac{3}{2}\right) . \Gamma\left(\frac{1}{2}\right)=\frac{\pi}{2}, \text { and } \Gamma\left(\frac{3}{2}\right)=\frac{1}{2} \Gamma\left(\frac{1}{2}\right) ; \\
\therefore \Gamma\left(\frac{1}{2}\right)=\sqrt{\pi} . \ldots \ldots \ldots \ldots \ldots \ldots \ldots \ldots \ldots \ldots \ldots \ldots \ldots
\end{array}
$$

* Of. Math. Gaz., 1902, p. 160. 
As an example of the Gamma function, let us consider

when $x=\infty$.

$$
S_{n}=\Pi\left(1 \pm \frac{x}{n}\right) \equiv(1+x)\left(1-\frac{x}{2}\right)\left(1+\frac{x}{3}\right) \ldots\left(1 \pm \frac{x}{n}\right)
$$

By definition,

$$
\begin{aligned}
& G\left(n, 1+\frac{x}{2}\right): G\left(n, 1-\frac{x}{2}\right)=n^{x} \prod_{1}^{n} \overline{2 n-x}: \prod_{1}^{n} \overline{2 n+x} . \\
& S_{2 n} \cdot G(2 n, 1+x)=(2 n)^{x} \prod_{1}^{n}\left(1-\frac{x}{2 n}\right) / \prod_{1}^{n}\left(1+\frac{x}{2 n}\right) ; \\
& \therefore 2^{x} G\left(n, 1+\frac{x}{2}\right) / G\left(n, 1-\frac{x}{2}\right)=S_{2 n} . G(2 n, 1+x) \text {; } \\
& \therefore \text { for } n=\infty, \quad S_{\infty}=2^{x} \Gamma\left(1+\frac{x}{2}\right) / \Gamma\left(1-\frac{x}{2}\right) \cdot \Gamma(1+x) \\
& =2^{x} / x B\left(x, 1-\frac{x}{2}\right) \text {. }
\end{aligned}
$$

G. OsBorn.

\section{REVIEWS.}

Theoretische Arithmetik. (II. Abtheilung). By O. Stolz und J. A. GMEINER. Leipzig, Teubner. 1902. Pp. 402.

This book is a new enlarged edition of certain chapters of Dr. Stolz' well-known Allgemeine Arithmetik. The merits of the latter are universally recognised, and no praise could be higher than to say that in lucidity and thoroughness the present volume is an improvement on it.

The first two chapters are not essential to the general plan of the book, the systematic development of the arithmetic theory of number, real and complex; but their inclusion is fully justified by their intrinsic interest. The first (chapter $\mathrm{V}$. of the complete work) deals with the mathematical theory of magnitudes, and has no direct connection with number. Mr. Russell has shown in his recent work The Principles of Mathematics that the simplicity or complexity of a mathematical theory of magnitudes depends very much on the philosophical view which underlies it. The authors do not explicitly raise any philosophical questions, but what Mr. Russell calls the relative theory of magnitude is presupposed in their treatment of the subject. The result is an exceedingly complicated system of axioms. The working out of the theory on this basis, however, leaves nothing to be desired. The second chapter contains a very clear account of Euclid's theory of ratio. It is not a little remarkable that the part of Euclid's work which is perhaps least open to criticism is the part which most of us were brought up to despise.

The theory of real numbers is then developed from Cantor's point of view. A noteworthy feature of the authors' treatment of this part of the subject is that the fundamental theorems concerning limits are proved first for the particular cases in which the limits are rational numbers. This is much to be commended, although it adds considerably to the length of the chapter. Another feature of the book is the prominence given here and elsewhere to the theory of approximation by decimals. It is a pity that the authors have not seen their way to include at any rate an outline of the elements of the theory of aggregates and transfinite cardinals and ordinals. This would have added considerably to the value of the book.

The next two chapters deal with the elementary theory of powers, roots, logarithms, and series. These chapters do not present many very novel features, but are admirably thorough. I may perhaps mention particularly the sections on approximation to roots, on the solution of the functional equation

$$
f(x+y)=f(x) f(y)
$$

and on the development of the theory of logarithms from the equation

$$
\log a=L_{n=\infty} n(\sqrt[n]{a}-1) .
$$

